The University of Maine

DigitalCommons@UMaine

University of Maine Office of Research and

Sponsored Programs: Grant Reports

Special Collections

6-2014

\title{
Flocculation, Optics and Turbulence in the Community Sediment Transport Model System: Application of OASIS Results
}

Emmanuel Boss

Principal Investigator; University of Maine, Orono, emmanuel.boss@maine.edu

Follow this and additional works at: https://digitalcommons.library.umaine.edu/orsp_reports

Part of the Environmental Indicators and Impact Assessment Commons, and the Oceanography Commons

\section{Recommended Citation}

Boss, Emmanuel, "Flocculation, Optics and Turbulence in the Community Sediment Transport Model System: Application of OASIS Results" (2014). University of Maine Office of Research and Sponsored Programs: Grant Reports. 7.

https://digitalcommons.library.umaine.edu/orsp_reports/7 


\title{
Flocculation, Optics and Turbulence in the Community Sediment Transport Model System: Application of OASIS Results
}

\author{
Final Report \\ Submitted to the Office of Naval Research
}

Emmanuel Boss

School of Marine Sciences

5706 Aubert Hall

University Of Maine

Orono, Maine, USA 04469-5706

phone: (207) 581-4378 fax: (207) 581-4388 email: emmanuel.boss@maine.edu http://misclab.umeoce.maine.edu/index.php

Grant Number: N000141010508

In collaboration with:

Paul S. Hill

Department of Oceanography

Dalhousie University

Halifax, Nova Scotia, CANADA B3H 4J1

phone: (902) 494-2266 fax: (902) 494-3877 email: paul.hill@dal.ca

Brent Law and Timothy G. Milligan

Fisheries and Oceans Canada

Bedford Institute of Oceanography

1 Challenger Drive

Dartmouth, Nova Scotia, CANADA B2Y 4A2

phone: (902) 426-3273 fax: (902) 426-6695 email: milligant (a)mar.dfo-mpo.gc.ca

Chris R. Sherwood

Woods Hole Oceanographic Institution

U. S. Geological Survey, Coastal and Marine Geology

384 Woods Hole Road, Woods Hole, MA 02543-1598

phone: 508-457-2269 fax: 508-457-2310 e-mail: csherwood (a) usgs.gov 


\section{LONG-TERM GOALS}

The goal of this research is to develop greater understanding of the how the flocculation of finegrained sediment responds to turbulent stresses and how this packaging of sediment affects optical and acoustical properties in the water column. Achieving these goals will improve the skill of sediment transport models and hence prediction of underwater visibility.

\section{OBJECTIVES}

1. Quantify the effects of aggregation dynamics on the size distribution of particles in the bottom boundary layer;

2. Quantify how changes in particle packaging affect the optical and acoustical properties of the water column.

3. Develop models describing the associations between particle aggregation, stress, and the acoustical and optical fields.

\section{APPROACH}

The approach is to obtain measurements that permit comparisons of temporal evolution of bottom stress, suspended particle size, and optical and acoustical properties in the bottom boundary layer. We measure optical and acoustical properties of the water column by coupling an ac- 9 (9 wavelength absorption and attenuation) and a two backscattering + CDOM fluorometer to the USGS tripod on their profiling arm (hence resolving the first $2 \mathrm{~m}$ of the bottom boundary layer). Coupling the ac- 9 with a switch and a filter, we are able to obtain calibration independent optical properties of particles (Slade et al., 2010) which provide us concentration, size and compositional information regarding the particles. In addition, it allows us to obtain the parameters needed to compute underwater visibility and provide the inputs necessary to Dr. N. Farr's group to model the optical field affecting underwater optical communication.

Collaborating with Dr. Hill, Sherwood and Trowbridge, our data will be used to develop and constrain a sediment concentration module that will be incorporated to the Community Sediment Transport Modeling System (CSTMS).

\section{WORK COMPLETED}

We participated in the field experiment at MVCO in Sep. 2011 at the Martha's Vineyard Coastal Observatory where we integrated our instrument into the USGS tripod which resolves the bottom $2 \mathrm{~m}$ of the bottom boundary layer. We processed the data and submitted it to a public data base. Processed data has been made public on the web in conjunction with the USGS data

(http:/pubs.usgs.gov/of/2012/1178/digdatafiles.html). We have been working on two manuscript pertaining to this deployment. Work has been presented at the Ocean Sciences conference in 2014 and will be presented at Ocean Optics 2014 in the coming fall.

\section{RESULTS}

The data set collected at MVCO in the fall of 2011 using the USGS profiling system (Fig. 1) is unique in its ability to span the bottom $2 \mathrm{~m}$ of the bottom boundary layer (BBL, Fig. 2) hence allowing us to further our understanding of particulate properties and their dynamics in the BBL. We observe strong 
gradients in time and space between different properties (e.g. Fig. 2 for optical transmission and acoustic backscattering). Each property measured allows us to compute a settling velocity by fitting a Rouse profile to the data (balancing turbulent resuspension, estimated from measured shear with settling), and provide settling estimate which are consistent with our understanding of what these parameter as sensitive to (Fig. 3).

With our OASIS support we continued to work on developing a theoretical understanding to the optical properties of aggregate particles (Stemmann and Boss, 2012) and analysis of the effect of size and packaging on acoustical backscattering (Russo and Boss. 2012ab). These studies suggest that current off-the-shelf ADV technology can provide realistic estimate of mass concentration but that packaging state of the particles have a great effect on backscattering and need to be taken into account for realistic estimates of particulate mass using acoustics.

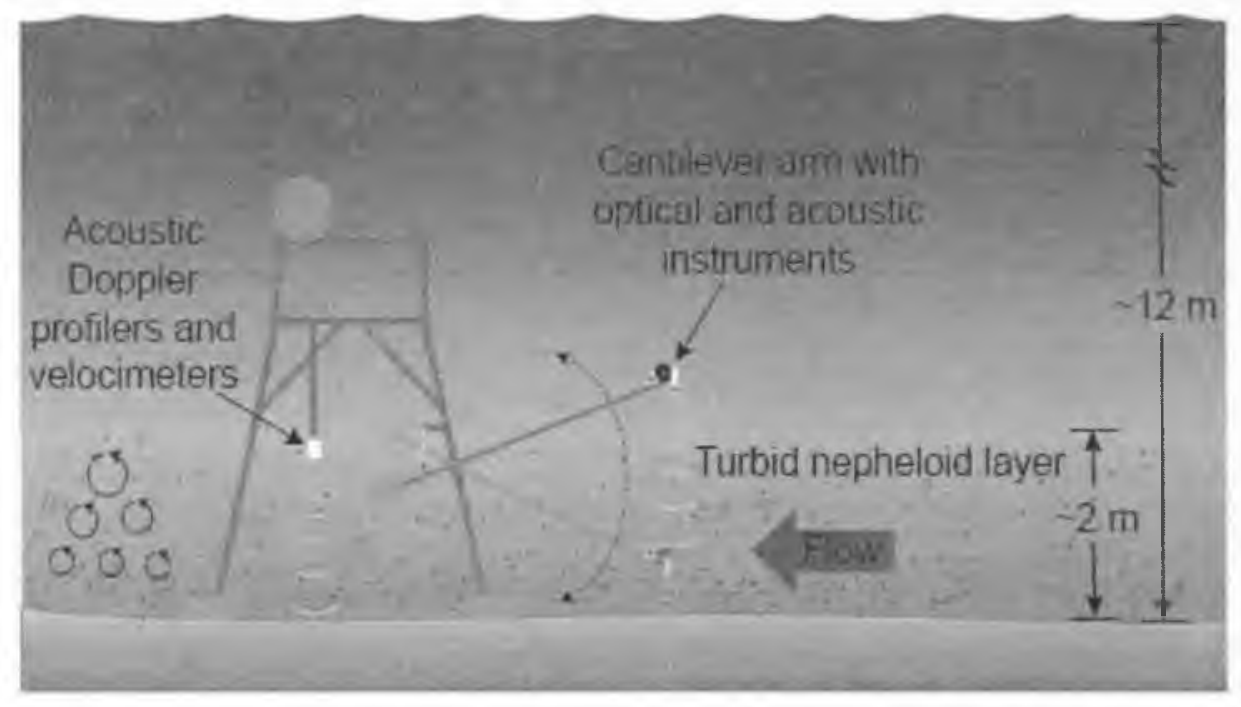

Figure 1. 1lustration of the profiling tripod with instruments on a cantilever arm for profiling particle distributions in the bottom boundary layer. (Illustration by P. Dickhudt). 


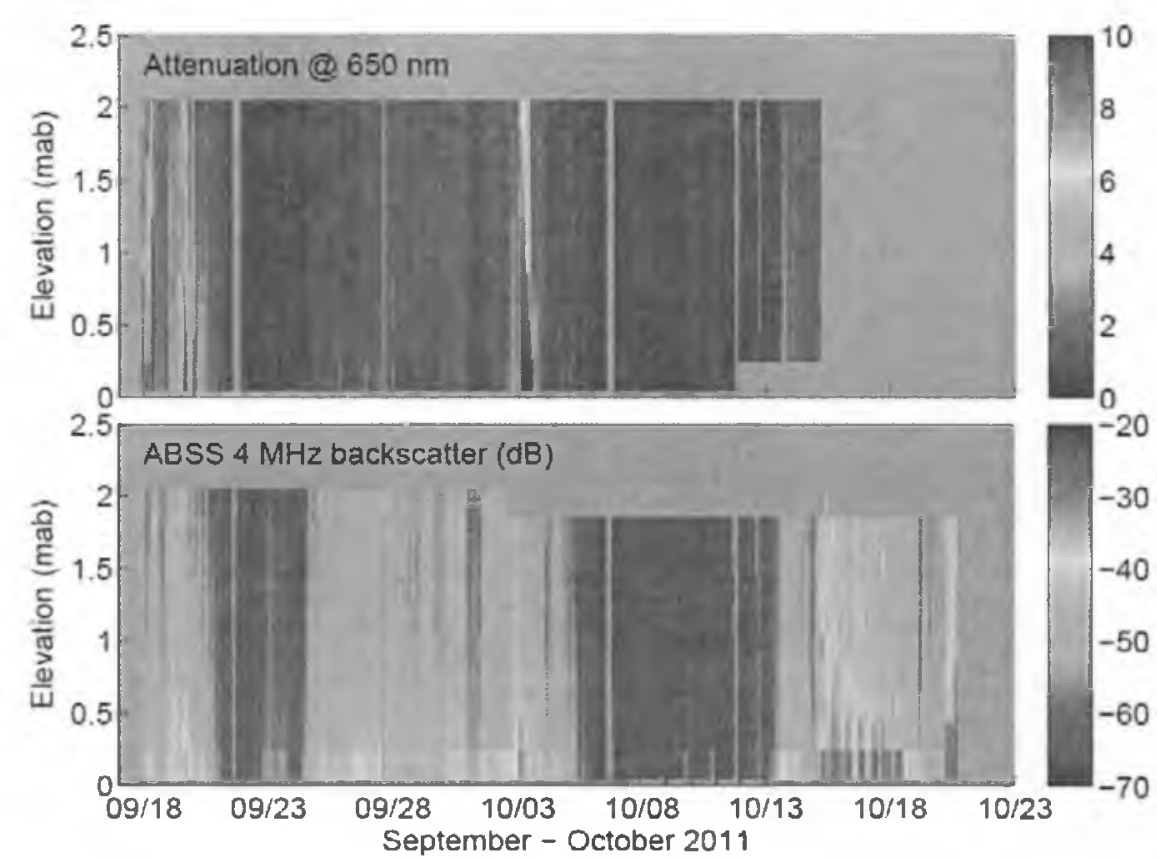

Figure 2. Time series of profiles of beam attenuation at $650 \mathrm{~nm}$ from the ac- 9 (top panel, units are $\mathrm{m}^{-1}$ ) and acoustic backscatter intensity at $4 \mathrm{MHz}$, measured $0.2 \mathrm{~m}$ from the transducer (units are decibels). Differences in the amplitude, duration, and vertical gradients in the response of the optical and acoustic proxies for suspended material are caused by changes in the concentration, size, composition and degree of aggregation of the particles in suspension. 


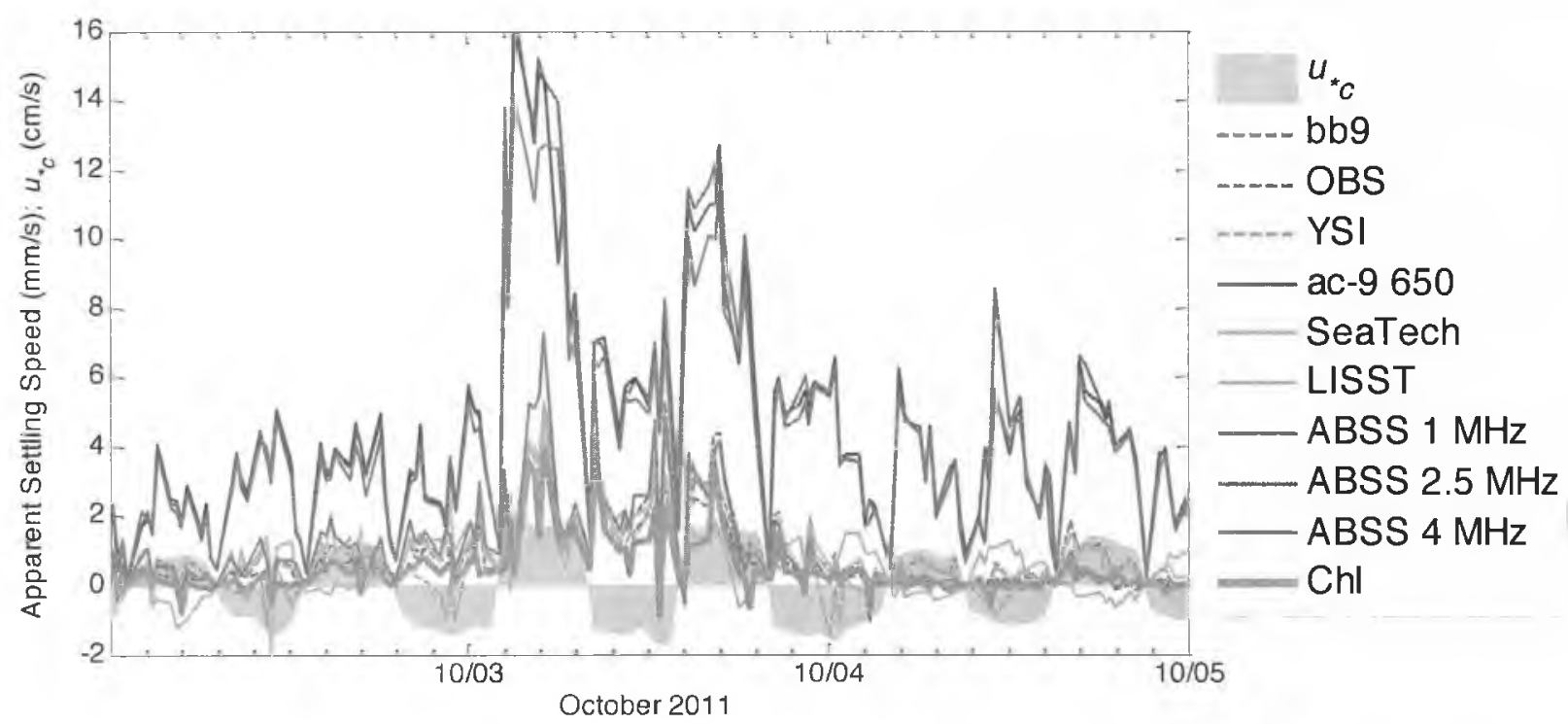

Figure 3. Time series of settling velocity inferred from different measurements by fitting a Rouse profile to them. Each parameter provide a different estimate as it is sensitive to different particles (e.g. ABSS acoustic is most sensitive to sand particles, LISST to aggregate, beam attenuation to particles smaller than $20 \mu \mathrm{m}$ and chlorophyll to phytoplanktion.

\section{IMPACT/APPLICATIONS}

The high-resolution time series of particle, optical, and acoustical properties provide us for the first time the possibility to constrain settling velocity of different particles in the BBL needed to understand clearing rates in the BBL. This is a crucial input to visibility models as well as those for sediment transport. Showing that each type of particles is distributed differently suggest we need to separate them in modeling.

\section{RELATED PROJECTS}

Instruments used in this work have been purchased through a DURIP grant (N000141010776 to E. Boss)

Observations made as part of the RIVET DRI are similar to OASIS measurements. They will help to broaden our understanding of the links between particle, optical properties and their remote sensing signatures (N000141210106 to E. Boss, collaborating with P. Hill and T. Milligan).

\section{PUBLICATIONS}

Russo, C.R. and E.S. Boss, 2012. An evaluation of acoustic doppler velocimeters as sensors to obtain the concentration of suspended mass in water, Journal of Atmospheric and Oceanic Technology, 29, 755-761 [published, refereed]

Stemmann, L., and E. Boss, 2012. Plankton and particle size and packaging: From determining optical properties to driving the biological pump, Annu. Rev. Mar. Sci. 2012, 4:263-290. [published, refereed] 